\title{
The Absence of Adiponectin Alters Niacin's Effects on Adipose Tissue Inflammation in Mice
}

\author{
Emily C. Graff ${ }^{1,2}{ }^{(}$, Han Fang ${ }^{3}\left(\mathbb{D}\right.$, Desiree Wanders ${ }^{4}$ and Robert L. Judd ${ }^{5, *}$ \\ 1 Department of Pathobiology, Auburn University, Auburn, AL 36849, USA; ecg0001@auburn.edu \\ 2 Scott-Ritchey Research Center, Auburn University, Auburn, AL 36849, USA \\ 3 Pennington Biomedical Research Center, Louisiana State University, Baton Rouge, LA 70808, USA; \\ han.fang@pbrc.edu \\ 4 Department of Nutrition, Georgia State University, Atlanta, GA 30302, USA; dwanders@gsu.edu \\ 5 Department of Anatomy, Physiology and Pharmacology, Auburn University, Auburn, AL 36849, USA \\ * Correspondence: juddrob@auburn.edu; Tel.: +1-334-844-5416; Fax: +1-334-844-5388
}

Received: 8 July 2020; Accepted: 10 August 2020; Published: 13 August 2020

check for updates

\begin{abstract}
Obesity is an immunometabolic disease associated with chronic inflammation and the dysregulation of pro- and anti-inflammatory cytokines. One hallmark of obesity is reduced concentrations of the anti-inflammatory adipokine, adiponectin. Pharmacologic doses of niacin produce multiple metabolic benefits, including attenuating high-fat diet (HFD)-induced adipose tissue inflammation and increasing adiponectin concentrations. To determine if adiponectin mediates the anti-inflammatory effects of niacin, male C57BL/6J (WT) and adiponectin null (Adipoq ${ }^{-/}$) mice were maintained on a low-fat diet (LFD) or HFD for 6 weeks, before being administered either vehicle or niacin $(360 \mathrm{mg} / \mathrm{kg} /$ day) for 5 weeks. HFD-fed mice had increased expression of genes associated with macrophage recruitment ( $C c l 2)$ and number (Cd68), and increased crown-like structure (CLS) number in adipose tissue. While niacin attenuated $C c l 2$ expression, there were no effects on $C d 68$ or CLS number. The absence of adiponectin did not hinder the ability of niacin to reduce $C c l 2$ expression. HFD feeding increased gene expression of inflammatory markers in the adipose tissue of WT and Adipoq ${ }^{-/}$mice. While niacin tended to decrease the expression of inflammatory markers in WT mice, niacin increased their expression in HFD-fed Adipoq ${ }^{--}$mice. Therefore, our results indicate that the absence of adiponectin alters the effects of niacin on markers of adipose tissue inflammation in HFD-fed mice, suggesting that the effects of niacin on tissue cytokines may involve adiponectin.
\end{abstract}

Keywords: obesity; inflammation; immune; niacin; adipokines

\section{Introduction}

Obesity is a chronic low-grade inflammatory disease characterized by increased inflammatory cytokines, circulating immune cells, and immune cells within adipose tissue [1-6]. Specific pathophysiologic features of human and rodent models of obesity include increased numbers of adipose tissue macrophages (ATMs) and a shift in macrophage polarity from an alternatively activated (M2) to a classically activated (M1) state [7]. Clinically, obesity and chronic adipose tissue inflammation are associated with the development of metabolic syndrome, insulin resistance, type 2 diabetes, and low-grade systemic inflammation [8-10]. In humans, chronic obesity and adipose tissue inflammation are associated with increases in serum MCP-1, TNF $\alpha$, IL-6 [8,11-13], and C-reactive protein (CRP) [14], and the increased circulation of pro-inflammatory mononuclear cells [1,15].

Along with inflammation, adipokine dysregulation—specifically decreased adiponectin [16-19] and increased leptin [20] - is a hallmark of obesity in humans and in rodent models of obesity [16-20]. Decreases in adiponectin precede the development of insulin resistance [18]. Adiponectin concentrations 
are inversely correlated to adipose tissue mass, and decreased serum adiponectin is associated with the development of metabolic disease, atherosclerosis, and type 2 diabetes [17-19]. Adiponectin is an anti-inflammatory mediator that plays a role in ATM polarization, immune cell migration, and chemokine production [21-24]. In cell culture, adiponectin inhibits the phagocytic activity of mature human macrophages [25] and in vivo studies indicate that peritoneal macrophages from adiponectin null mice exhibit an increased M1 profile [22]. Others have shown that treatment with adiponectin decreases TLR-4 receptors on cultured macrophages and shifts macrophages towards an M2 phenotype [23]. Overall, maintenance of an adequate adiponectin concentration appears to be tied to improved adipocyte function, metabolic homeostasis, and decreased inflammation [21].

For over 50 years, pharmacologic doses of niacin have been used in the treatment of atherogenic dyslipidemia [26], which is associated with obesity and metabolic syndrome. However, recent evidence indicates that the beneficial effects of niacin may involve the modulation of inflammatory pathways that are independent of its anti-lipolytic effects on adipocytes [27-29]. Beneficial effects of niacin have been reported in adipocytes, immune cells, and vascular endothelial cells [28-33]. Both macrophages and mature adipocytes express the receptor for niacin, $\mathrm{HCA}_{2}$ [34-36]. Activation of the $\mathrm{HCA}_{2}$ receptor has anti-inflammatory effects throughout numerous organ systems, including the gastrointestinal, cardiovascular, and nervous systems [37]. In 2011, Lukasova et al. showed that niacin-mediated $\mathrm{HCA}_{2}$ activation decreases $\mathrm{M} 1$ macrophage differentiation in atherosclerotic plaques in mice [29]. Similar findings are observed in adipose tissue of mice, as the chronic administration of niacin attenuates the HFD-induced expression of M1 macrophage markers and chemokines such as MCP-1 in an $\mathrm{HCA}_{2}$-dependent manner [28]. In addition, treatment with niacin has been shown to inhibit macrophage recruitment, adhesion, and chemotaxis, and to alter TLR-mediated cytokine release $[26,27,30,38]$. In vascular endothelial cells, niacin inhibits acute vascular inflammation, oxidative stress, and monocyte adhesion [31-33]. Previous work from our laboratory and others demonstrates that niacin increases serum concentrations of adiponectin in rodent models and humans [30,39-41], and this increase is mediated by the $\mathrm{HCA}_{2}$ receptor $[28,42]$. Therefore, niacin may decrease inflammation either through direct effects on adipocytes, macrophages and endothelial cells, or indirectly, by altering systemic pro- and anti-inflammatory factors such as adiponectin. Likewise, niacin and adiponectin may act synergistically to decrease inflammation associated with obesity.

It is not known if the anti-inflammatory effects of niacin are mediated by adiponectin. Thus, the objective of this study is to determine whether adiponectin is necessary for niacin to decrease HFD-induced adipose tissue inflammation. Using wild-type (WT) and Adipoq ${ }^{-/-}$mice, we show that niacin decreased HFD-induced body weight gain in an adiponectin-dependent manner, but the effects of niacin on inflammatory markers differed between genotypes. Niacin tended to decrease inflammatory markers in WT mice but increased them in Adipoq ${ }^{-/-}$mice. One unexpected finding was that niacin significantly increased Arg1 (a classic M2 macrophage marker) in Adipoq ${ }^{-/-}$mice. These results indicate a complex relationship between adiponectin and the mechanisms by which niacin exerts its anti-inflammatory effects.

\section{Materials and Methods}

\subsection{Animal Studies}

All animal studies were approved by the Auburn University Institutional Animal Care and Use Committee prior to initiation, and all methods were performed in accordance with relevant guidelines. Thirty-two 3-week-old male C57BL/6J mice were purchased from Jackson Laboratories (Bar Harbor, ME, USA). Mice were maintained on either a low-fat diet (LFD; $10 \% \mathrm{kcal}$ as fat; $n=16$ ) or a high-fat diet (HFD; $60 \% \mathrm{kcal}$ as fat; $n=16$ ) obtained from Research Diets (New Brunswick, NJ, USA) for 11 weeks. After six weeks on the low-fat or high-fat diets, half of the mice received niacin (Sigma-Aldrich, St. Louis, MO, USA) at approximately $360 \mathrm{mg} / \mathrm{kg} /$ day dissolved in drinking water or vehicle (water) for five weeks. Water intake was measured every 4 days and niacin concentration in 
the water was adjusted based on water consumption. After five weeks of vehicle or niacin treatments, mice were fasted overnight $(12 \mathrm{~h})$ and euthanized by decapitation. Whole blood was collected, and serum was isolated. Tissues were flash frozen in liquid nitrogen and stored at $-80{ }^{\circ} \mathrm{C}$ until analysis. Parallel studies were conducted in male global adiponectin null mice derived from a breeding pair of B6.129-Adipoq ${ }^{\text {tm1Chan }} / \mathrm{J}\left(\right.$ Adipoq $\left.^{-/}\right)$mice purchased from Jackson Labs. Thirteen Adipoq ${ }^{-/}$mice were placed on the LFD diet (6 received vehicle; 7 received niacin), and sixteen Adipoq ${ }^{-/}$mice were placed on the HFD (8 received vehicle; 8 received niacin).

\subsection{Serum Analysis}

Serum total adiponectin concentrations were measured by ELISA (Millipore; Temecula, CA, USA). Serum triglyceride concentrations were measured using a colorimetric assay (Cayman Chemicals; Ann Arbor, MI, USA). Blood glucose concentrations were determined using the AccuChek Active Handheld glucometer (Roche, Indianapolis, IN, USA) on whole blood collected from the mandibular vein. Serum NEFAs were measured using a colorimetric assay (Wako Chemicals; Richmond, VA, USA). Serum insulin, IL-6, MCP-1, and TNF- $\alpha$ were measured using Milliplex multiplex custom kit (Millipore; Temecula, CA, USA) and read on a MAGPix Bio-analyzer (Luminex; Temecula, CA, USA).

\subsection{Gene Expression Analysis}

RNA was isolated from epididymal white adipose tissue (F) using Qiagen RNeasy Lipid Tissue Mini Kit with on-column DNA digestion (Qiagen, Valencia, CA, USA). RNA (0.5 or $1 \mu \mathrm{g}$ ) was reverse transcribed into cDNA using an iScript cDNA Synthesis Kit from Bio-Rad (Bio-Rad, Hercules, CA, USA). PCR primers used in the real-time PCR analysis were previously published [28]. Analyses were performed on a Bio-Rad iCycler iQ thermocycler. Samples were analyzed in $30 \mu \mathrm{L}$ reactions using SYBR Green PCR Master Mix (Bio-Rad, Hercules, CA, USA). All expression levels were normalized to the corresponding Rppl0 mRNA levels, and analyzed using the $2^{-\Delta \Delta C T}$ method [43]. Rppl0 mRNA levels were unchanged in response to HFD or niacin treatment.

\subsection{Immunoblot Analysis}

EWAT pads ( 100 mg) were homogenized with a handheld homogenizer in Pierce RIPA buffer (Rockford, IL, USA) supplemented with cOmpleteßprotease inhibitor tablet (Roche, Indianapolis, IN, USA) and phosphatase inhibitors (Sigma-Aldrich, St. Louis, MO, USA). The protein fractions were isolated and a DC protein assay (Bio-Rad, Hercules, CA, USA) was conducted to determine the protein concentration for each sample. Proteins $(20 \mu \mathrm{g})$ were boiled for $20 \mathrm{~min}$ in 5\% 2-mercaptoethanol to allow for the assessment of fully denatured and reduced monomers of adiponectin, which were then separated by SDS-PAGE (10\%) and transferred to nitrocellulose membranes. Membranes were blocked in blocking buffer (LI-COR, Lincoln, NE, USA) for 1 hour and incubated with primary antibody overnight at $4{ }^{\circ} \mathrm{C}$. Primary antibodies were either a rabbit polyclonal adiponectin antibody acquired from Abcam, Inc. (Cambridge, MA, USA) or a GAPDH mouse monoclonal antibody from Millipore (Billerica, MA, USA). The membranes were then washed with PBS with $0.1 \%$ Tween-20 and incubated with secondary antibody (either goat anti-mouse IRDye 800CW or donkey anti-rabbit IRDye 680RD (LI-COR, Lincoln, NE, USA)), and washed with PBS with 0.1\% Tween-20. Blots were imaged using the LI-COR Odyssey scanner (LI-COR, Lincoln, NE, USA) with band density quantified using Image Studio software ver. 2.0 (LI-COR, Lincoln, NE, USA).

\subsection{Histopathologic Analysis of EWAT}

Portions of the EWAT were immediately fixed in $10 \%$ neutral buffered formalin, processed overnight and paraffin-embedded. Five-micron-thick hematoxylin and eosin (H\&E)-stained sections were used for evaluation, and macrophage identification was verified with F4/80 cytoplasmic staining in step sections using rat anti-mouse F4/80 antibody (Abd Serotec, Raleigh, North Carolina; Clone CI:A3-1) with Rodent Block M (BioCare Medical, Concord, CA, USA) to reduce nonspecific staining. Crown-like 
structures (CLS) were defined as shrunken adipocytes surrounded by morphologically identified macrophages [6]. Slides were scanned using the Aperio ScanScope scanner (Vista, CA, USA) and evaluated on VisioPharm software (Hoersholm, Denmark) as previously described [44]. Briefly, the entire adipocyte section was evaluated to identify individual adipocytes using the following rules. Objects were identified and counted as adipocytes if: 1) the area was between 500 and 20,000 $\mu \mathrm{m}$; and 2) it had a shape factor of $0-0.7$, where a shape factor of 1 indicates a straight line and 0 indicates a perfect circle. Approximately $80-90 \%$ of the adipocytes were counted for each section. CLS were counted on H\&E-stained slides by a board-certified pathologist and the entire surface area of each fat pad was counted to provide a total number of CLS per fat pad, which was then normalized per 100 adipocytes based on the total adipocyte number per section.

\subsection{Statistical Analysis}

All data sets were evaluated for normality and data that did not exhibit Gaussian distribution were $\log$ transformed. Analyses of serum and tissue protein concentrations and relative gene expression were determined by two-way ANOVA with Tukey's post-hoc analysis. All statistical analyses were performed on Graph Pad Prism 7 software (La Jolla, CA, USA).

\section{Results}

\subsection{Effects of HFD and Niacin on Metabolic Parameters in Mice}

At the start of the study there was no statistical difference in body weight observed in any of the treatment groups. At the end of the study, as expected, compared to LFD-fed mice, HFD-fed mice had significantly increased body weight, EWAT weight, and blood glucose concentrations (Figure 1). Neither niacin treatment nor genotype affected any of these parameters. Over the course of the study, the HFD-fed mice consumed more calories than LFD-fed mice, but neither genotype nor niacin had any effect on food or water intake (Figure 1C). HFD feeding increased serum insulin concentrations and HOMA-IR, with these effects being more pronounced in Adipoq ${ }^{-/-}$mice (Figure 1E,F).

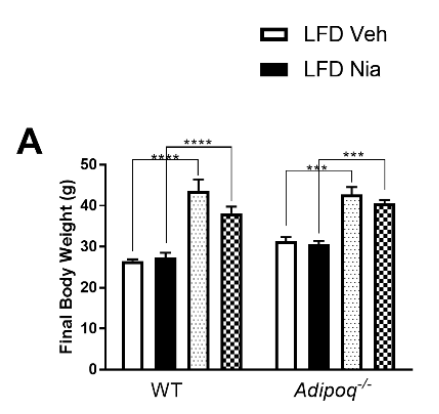

$$
\begin{aligned}
& \text { HFD Veh } \\
& \text { HFD Nia }
\end{aligned}
$$

\section{B}
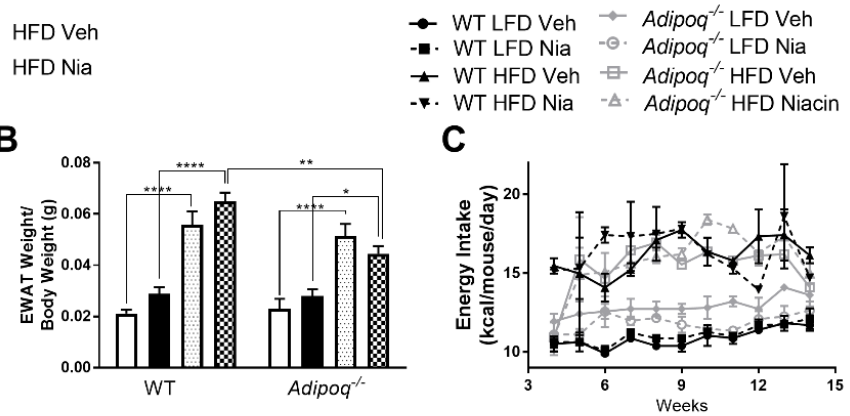

D

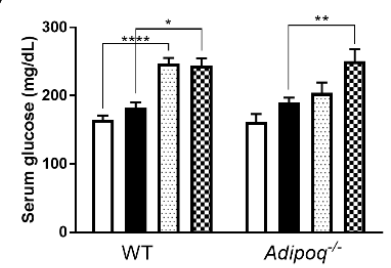

E

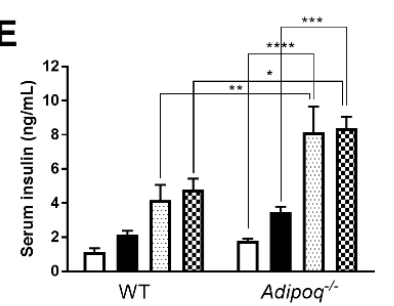

$\mathbf{F}$

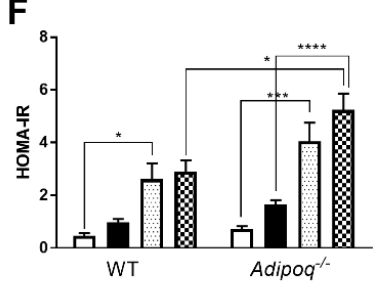

Figure 1. Effects of high-fat diet (HFD) and niacin on metabolic parameters. Effects of HFD and niacin on body weight (A), EWAT weight (B), energy intake (C), serum glucose concentrations (D), serum insulin concentrations (E), and HOMA-IR (F) in WT and Adipo $q^{-1-}$ mice. Data are presented as mean + SEM. ${ }^{*} p \leq 0.05 ;{ }^{* *} p \leq 0.01 ; * * * * 0.001 ; * * * * * 10.0001$; WT low-fat diet (LFD) Veh, $n=8$; WT LFD Nia, $n=8$; WT HFD Veh, $n=8$; WT HFD Nia, $n=7$; Adipoq ${ }^{-1}$ LFD Veh, $n=6$; Adipoq ${ }^{-1}$ LFD Nia, $n=7 ;$ Adipoq $^{-1}$ HFD Veh, $n=8$; Adipoq ${ }^{-1}$ HFD Nia, $n=8$. 


\subsection{Effects of HFD and Niacin on Adiponectin}

HFD produced a $\sim 2$-fold decrease in adiponectin gene expression (Figure 2A) and a trend towards decreased adiponectin protein expression in adipose tissue (Figure 2B). In LFD-fed mice, niacin had no effect on adipose tissue adiponectin mRNA (Figure 2A) or total protein expression within the tissue (Figure 2B). However, niacin treatment significantly increased adiponectin mRNA and protein expression in HFD-fed mice (Figure 2A,B). Interestingly, niacin significantly increased serum adiponectin concentrations by $\sim 14 \%$ in LFD-fed mice but had no effect on serum adiponectin concentrations in HFD-fed mice (Figure 2C). Adipoq ${ }^{-1}$ mice did not have measurable adiponectin protein concentrations in EWAT (Figure 1B).
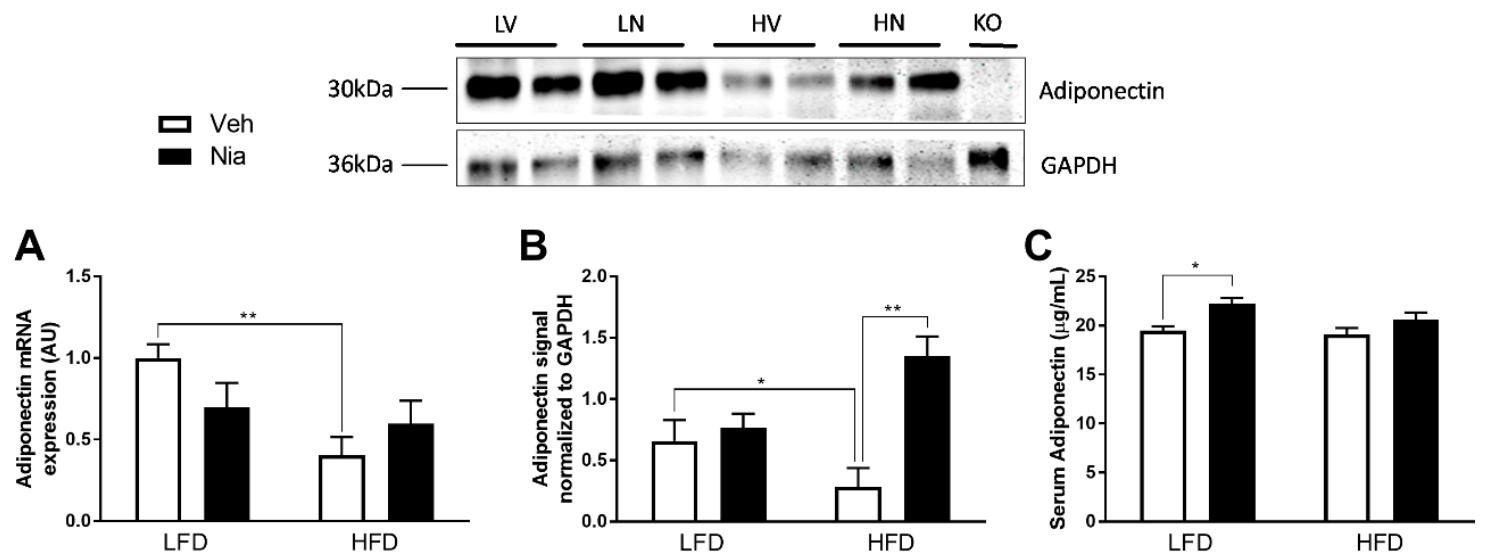

Figure 2. Effects of HFD and niacin on tissue and serum adiponectin concentrations. EWAT adiponectin mRNA expression (A), EWAT adiponectin protein expression (B), and serum adiponectin concentrations (C) in wild-type mice. Adiponectin mRNA values were normalized to Rppl0 expression. Data are presented as mean + SEM. AU: arbitrary units. ${ }^{*} p \leq 0.05 ;{ }^{* *} p \leq 0.01$; LV: LFD vehicle; LN: LFD niacin; HV: HFD vehicle; HN: HFD niacin; KO: Adipoq ${ }^{-/}$. WT LFD Veh, $n=8$; WT LFD Nia, $n=8$; WT HFD Veh, $n=8$; WT HFD Nia, $n=7$.

\subsection{Effects of HFD and Niacin on Markers of Macrophage Recruitment and Number}

HFD feeding increased gene expression of the general macrophage marker $C d 68$ and the pro-inflammatory chemokine $\mathrm{Ccl} 2$ in adipose tissue of WT and Adipoq ${ }^{-/-}$mice (Figure 3A,B).

$$
\text { 口 LFD Veh } \square \text { HFD Veh }
$$

A
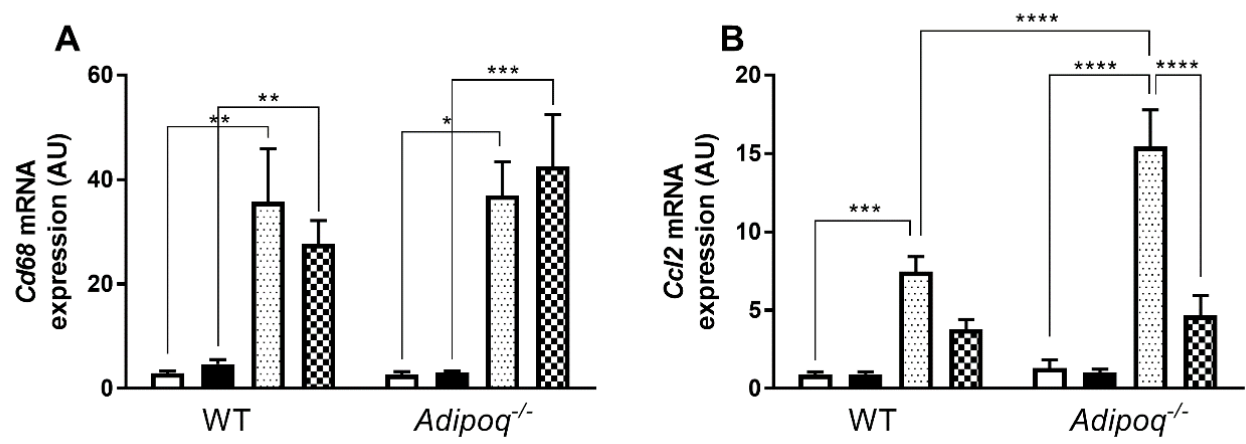

Figure 3. Effects of HFD and niacin on the gene expression of markers of macrophage number and migration in EWAT. Relative gene expression of the general macrophage marker Cd68 (A) and the macrophage chemokine $C c l 2$ (B) in wild-type and Adipo ${ }^{-/}$mice; all mRNA values were normalized to Rppl0 expression. Data are presented as mean + SEM. AU: arbitrary units. ${ }^{*} p \leq 0.05 ;{ }^{* *} p \leq 0.01$; ${ }^{* * *} p \leq 0.001 ;{ }^{* * * *} p \leq 0.0001$; WT LFD Veh, $n=8$; WT LFD Nia, $n=8$; WT HFD Veh, $n=8$; WT HFD Nia, $n=7$; Adipoq ${ }^{--}$LFD Veh, $n=6$; Adipoq ${ }^{--}$LFD Nia, $n=7$; Adipoq ${ }^{--}$HFD Veh, $n=8 ;$ Adipoq ${ }^{--}$HFD $\mathrm{Nia}, n=8$. 
Interestingly, HFD-fed Adipoq ${ }^{-/}$mice had significantly greater Ccl2 gene expression than WT HFD-fed mice. Treatment with niacin had no effect on $C d 68$ gene expression in any group. However, niacin attenuated the HFD-induced increase in Ccl2 gene expression in Adipoq ${ }^{-/}$mice. While it did not reach statistical significance, niacin reduced Ccl2 gene expression two-fold in WT HFD-fed mice. In agreement with the HFD-induced increase in inflammatory gene expression, HFD-fed mice also had a significant increase in the number of CLS in EWAT, as well as in adipocyte size (Figure 4). The HFD-induced increase in CLS number in Adipoq ${ }^{-/}$mice did not reach statistical significance, likely due to the low number of CLS present overall. Niacin treatment had no effect on the presence of CLS or on adipocyte size in either genotype (Figure 4C,D).
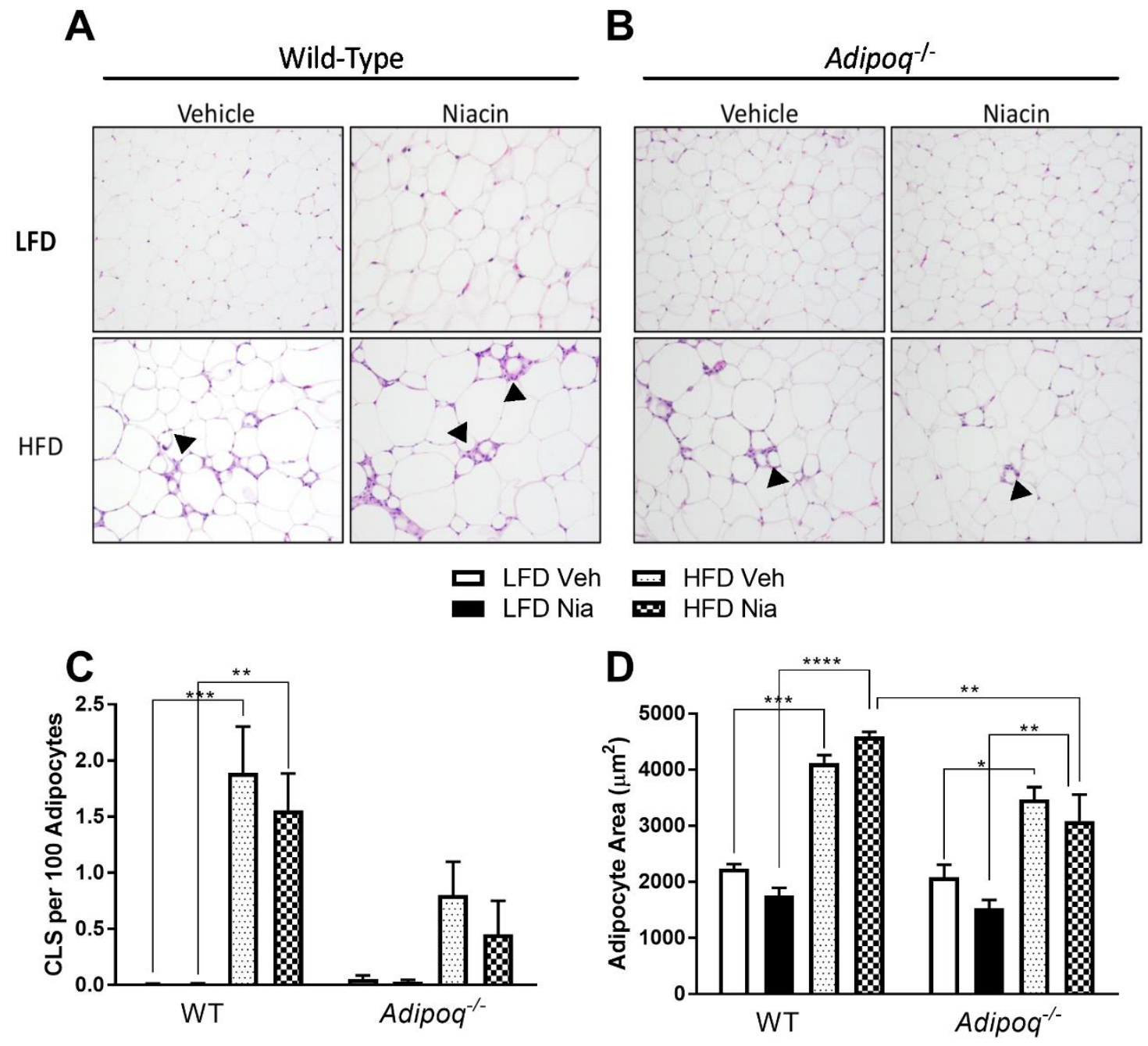

Figure 4. Effects of HFD and niacin on the development of crown-like structures (CLS) in EWAT. Images of hematoxylin and eosin (H\&E)-stained sections of EWAT depicting CLS density for (A) wild-type and (B) Adipoq ${ }^{--}$mice. Number of CLS per 100 adipocytes (C). Mean adipocyte area (D). Arrowheads indicate CLS. Data are presented as mean + SEM. ${ }^{*} p \leq 0.05 ;{ }^{* *} p \leq 0.01 ;{ }^{* * *} p \leq 0.001 ;{ }^{* * * *} p \leq 0.0001$; WT LFD Veh, $n=4$; WT LFD Nia, $n=3$; WT HFD Veh, $n=3$; WT HFD Nia, $n=3$; Adipoq $q^{-/}$LFD Veh, $n=3$; Adipoq ${ }^{--}$LFD Nia, $n=3$; Adipoq ${ }^{--}$HFD Veh, $n=4$; Adipoq ${ }^{--}$HFD Nia, $n=4$.

\subsection{Effects of HFD and Niacin on Other Markers of Adipose Tissue Inflammation}

In general, HFD increased gene expression of pro-inflammatory markers in adipose tissue of WT and Adipoq ${ }^{--}$mice (Figure 5A,B), with a significant increase noted in Itgax gene expression in WT mice, and a significant increase in $T n f$ gene expression in Adipoq ${ }^{-/-}$mice. Interestingly, niacin tended to 
reduce Itgax expression in WT mice $(p=0.07)$, but significantly increased Itgax expression in Adipoq-mice. Niacin treatment had no significant effect on Tnf expression in EWAT.

$$
\begin{array}{ll}
\text { 口 LFD Veh } & \text { HFD Veh } \\
\text { LFD Nia } & \boldsymbol{⿴ 囗 十 ⿰} \text { HFD Nia }
\end{array}
$$
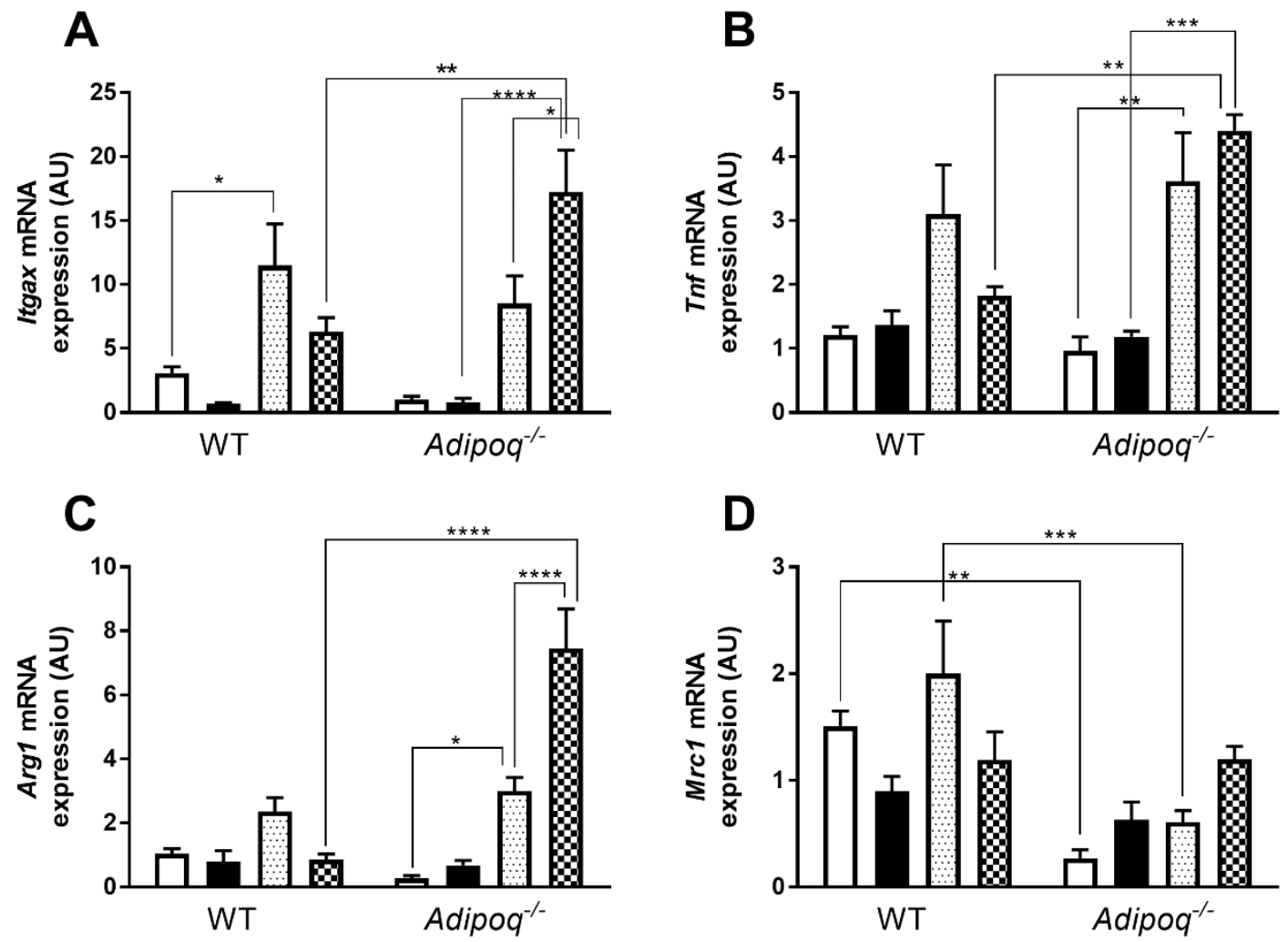

Figure 5. Effects of HFD and niacin on the gene expression of markers of adipose tissue macrophage polarity in EWAT. Relative gene expression of the M1 macrophage markers Itgax (A) and Tnf (B), and the M2 macrophage markers $\operatorname{Arg1}(\mathbf{C})$, and $M r c 1$ (D) in wild-type and Adipoq ${ }^{--}$mice. All mRNA values were normalized to Rppl0 expression. Data are presented as mean + SEM. AU: arbitrary units. ${ }^{*} p \leq 0.05 ;{ }^{* *} p \leq 0.01 ; * * * \quad 0.001 ;{ }^{* * *} p \leq 0.0001$; WT LFD Veh, $n=8$; WT LFD Nia, $n=8$; WT HFD Veh, $n=8$; WT HFD Nia, $n=7$; Adipoq ${ }^{-/}$LFD Veh, $n=6$; Adipoq ${ }^{-/}$LFD Nia, $n=7$; Adipoq $q^{-/}$HFD Veh, $n=8 ;$ Adipoq $^{--}$HFD Nia, $n=8$.

As part of general adipose tissue inflammation, additional markers including $\operatorname{Arg} 1$ and $M r c 1$ were evaluated. HFD had no effect on Arg1 expression in WT mice, but significantly increased its expression in Adipoq ${ }^{-/}$mice (Figure 5C). In WT mice, niacin treatment had no effect on Arg1 expression, while in HFD-fed Adipoq ${ }^{-/}$mice, niacin significantly increased Arg1 gene expression. This genotypic effect was particularly striking as HFD-fed niacin-treated Adipoq ${ }^{-/}$mice had a $\sim 9$-fold increase in Arg1 gene expression compared to WT HFD-fed niacin-treated mice. Neither HFD nor niacin altered Mrc1 expression in either genotype (Figure 5D). Interestingly, Adipoq ${ }^{--}$mice fed an HFD had significantly lower Mrc1 expression than WT HFD-fed mice.

\subsection{Effects of HFD and Niacin on Markers of Systemic Inflammation}

Neither HFD nor niacin had any effect on serum concentrations of IL-6 or TNF $\alpha$ in either genotype (Figure 6A,B). However, it should be noted that the LFD-fed mice treated with niacin had undetectable amounts of IL- 6 and TNF $\alpha$ in their serum. In WT mice, serum MCP-1 concentrations were not affected by diet or niacin treatment (Figure 6C). However, HFD significantly increased serum 
MCP-1 concentrations in Adipoq ${ }^{-/}$mice, suggesting that the lack of adiponectin predisposes mice to an HFD-induced increase in circulating MCP-1.

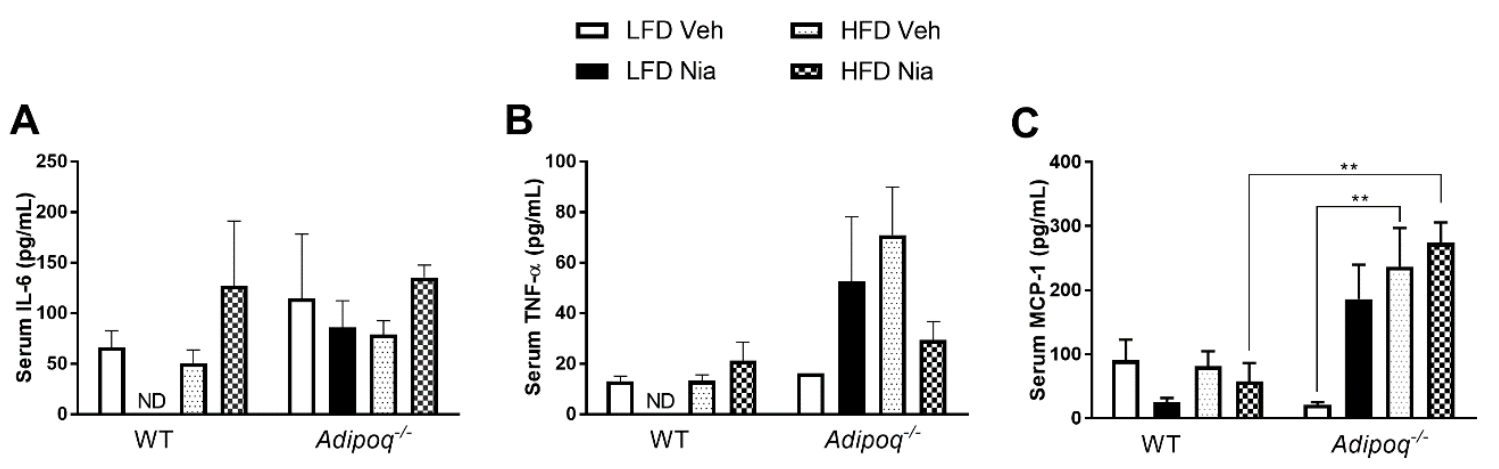

Figure 6. Effects of HFD and niacin on systemic markers of inflammation. Serum concentrations of the proinflammatory cytokines IL-6 (A) and TNF- $\alpha$ (B), and the macrophage chemokine MCP-1 (C), in wild-type and Adipoq ${ }^{-/}$mice. Data are presented as mean + SEM. ND: not detectable. ${ }^{* *} p \leq 0.01$; WT LFD Veh, $n=8$; WT LFD Nia, $n=8$; WT HFD Veh, $n=8$; WT HFD Nia, $n=7$; Adipoq ${ }^{-/}$LFD Veh, $n=6$; Adipoq ${ }^{-/}$LFD Nia, $n=7$; Adipoq ${ }^{-/}$HFD Veh, $n=8$; Adipoq ${ }^{-/}$HFD Nia, $n=8$.

\section{Discussion}

There is increasing evidence that the beneficial effects of niacin are independent of its effects on dyslipidemia [27-30,33,38]. A growing number of studies demonstrate that niacin has the ability to inhibit inflammation in a variety of tissues including adipose, colon, and brain $[28,45,46]$. However, the mechanisms underlying niacin's anti-inflammatory effects are not completely understood. Niacin also increases serum and tissue concentrations of the anti-inflammatory adipokine adiponectin, through activation of the $\mathrm{HCA}_{2}$ receptor on adipocytes $[28,40,42,47,48]$. Thus, our objective was to determine if the anti-inflammatory properties of niacin were due, at least in part, to its ability to increase local and circulating adiponectin concentrations.

Obesity is associated with decreased tissue and serum adiponectin concentrations [17,49]. Consistent with previous work in our lab and others, we observed an HFD-induced decrease in adipose tissue adiponectin gene and protein expression, but no change in serum adiponectin concentrations [28]. The lack of changes observed in serum adiponectin concentrations in these mice may reflect the short time frame (11 weeks) that the mice were on a HFD. The time at which HFD-fed mice develop decreased serum or plasma adiponectin concentrations varies in the literature. Some studies, using a range of diets that contain anywhere from $40 \%$ to $60 \%$ lard, demonstrate decreased adiponectin concentrations by as early as 4 weeks on the diet [50-52]. However, another study similar to ours did not observe an HFD-mediated decrease in adiponectin after 10 weeks on an HFD that consisted of $60 \%$ lard [53]. While we did observe decreased tissue adiponectin levels, it is likely that we would have to increase the duration of the HFD feeding in order to obtain statistically significant changes in the serum. It is also possible that there are changes in the multimeric forms of adiponectin. However, previous work from our lab found that there was no effect on serum concentrations of high-molecular-weight adiponectin with either HFD feeding or niacin treatment [28].

Previous work from our lab and others demonstrated niacin's ability to increase tissue and circulating adiponectin $[28,47,48]$. In this study, niacin increased adiponectin protein expression in HFD-fed mice. The mechanism by which niacin increases adiponectin is unclear. However, studies in our lab demonstrated that niacin-mediated increases in adiponectin are independent of changes in the gene expression of key transcription factors (PPAR $\gamma \mathrm{C} / \mathrm{EBP} \alpha$ or SREBP-1c) and ER chaperones (ERp44, Erol-L $\alpha$ and DsbA-L) known to positively regulate adiponectin gene transcription [28].

As expected, the HFD significantly impacted all of the metabolic parameters measured, including increasing body weight, EWAT weight, serum glucose concentrations, and HOMA-IR, but niacin had no effect on any of these parameters. Interestingly, the HFD-induced increase in serum insulin 
concentrations was more pronounced in Adipoq ${ }^{-/}$mice. Niacin increases insulin resistance, specifically in skeletal muscle, and studies have shown that this resistance is blunted by serum adiponectin concentrations [39]. Therefore, it is not surprising that Adipoq ${ }^{-/}$mice would have increased insulin concentrations and HOMA-IR compared to WT counterparts. Further studies are needed to investigate the metabolic phenotype of WT and Adipoq ${ }^{-/}$mice treated with niacin.

There was a significant increase in gene expression for markers of obesity-associated adipose tissue inflammation in WT and Adipoq ${ }^{--}$mice fed an HFD. The general macrophage marker CD68 is a transmembrane glycoprotein expressed on monocytes and macrophages [54]. MCP-1, the protein encoded by the gene $\mathrm{Ccl} 2$, is a potent chemokine involved in the trafficking of monocytes and macrophages to adipose tissue during the development of adipose tissue inflammation [55]. Increased MCP-1 also contributes to the development of insulin resistance [56-58]. A few studies have also demonstrated niacin's ability to decrease chemoattractant-mediated macrophage migration in vitro $[27,59]$, which suggests that niacin treatment might decrease ATM content. Consistent with previous in vivo studies, we observed a significant increase in Cd68 and Ccl2 gene expression in the EWAT of mice fed an HFD [28]. Niacin did not alter Cd68 gene expression, but attenuated the HFD-induced increase in Ccl2 expression in Adipoq ${ }^{-/}$mice. These findings suggest that niacin inhibits mechanisms of macrophage recruitment to EWAT of mice fed an HFD, but does not appear to alter overall macrophage number. Histopathologic evaluation of EWAT tissue samples further supports this conclusion, as there was a significant increase in the number of CLS in mice fed the HFD. However, niacin had no effect on CLS number in any group of mice. As MCP-1 is also secreted by adipocytes, resident ATMs, and endothelial cells [13,60], it would be interesting to determine if the changes in MCP-1 are associated with a specific cell type. The similar effect of HFD and niacin in both genotypes suggests that adiponectin does not play a role in niacin-mediated attenuation of Ccl2 expression in adipose tissue, at least in EWAT. These findings are important, as previous work has shown that these niacin-mediated effects on $\mathrm{Ccl} 2$ are dependent on activation of the $\mathrm{HCA}_{2}$ receptor, which also plays a role in adiponectin secretion [28]. Interestingly, Adipoq ${ }^{-/}$mice appear to have a milder phenotype with fewer CLS than WT mice when placed on an HFD. This study is limited to the evaluation of changes in inflammation of the EWAT, a gonadal adipose tissue depot. Previous studies have shown a distinct difference in gonadal adipose tissue lipolysis and inflammation between male and female mice, with HFD feeding and changes in lipid metabolites driving gonadal adipose tissue inflammation in males, but remodeling in females. Future studies should compare the effects of niacin and adiponectin of various tissue stores, including inguinal (a subcutaneous depot), omental, and perirenal, as well as distinct differences between males and females.

Macrophage polarity is defined by patterns of cell surface receptor expression, transcription factor activation, and cytokine secretion. Adipose tissue from lean individuals contains relatively low numbers of M2 (or alternatively activated) macrophages, and with the development of obesity, there is an increase in ATMs and a phenotypic switch to M1 (or classically activated) macrophages. While most studies describe polarity with a clear dichotomy of either M1 or M2, many studies suggest that macrophage activation is on a spectrum and varies significantly based on the stimulation and microenvironment [61-63]. In our study, HFD increased the expression of genes typically considered as M1 macrophage markers. For example, HFD increased Itgax expression in WT mice and Tnf expression in Adipoq ${ }^{--}$mice. Additionally, HFD increased the expression of Arg1, which is typically considered an M2 macrophage marker in Adipoq ${ }^{-/}$mice. These data support the presence of general adipose tissue inflammation.

One of the most surprising findings of our study was the opposing effects niacin had on markers of inflammation in EWAT of Adipoq ${ }^{--}$mice compared to WT mice. In WT mice, niacin either had no effect on or tended to reduce the expression of Itgax, Arg1, Tnf, and Mrc1. However, niacin significantly increased the expression of Itgax and Arg1 in Adipoq ${ }^{-/}$mice. In the case of Arg1, this increase was significantly greater than even HFD feeding alone. This finding is confounded by the overall fewer numbers of CLS in the EWAT of Adipoq ${ }^{-/}$mice compared to WT mice. In addition, the number of 
CLS was not significantly increased in Adipo ${ }^{-1-}$ mice by HFD feeding and the development of obesity. Given that adipocyte inflammation is critical for normal adipose tissue remodeling [64], it is possible that in the absence of adiponectin, adipose tissue from obese individuals has fewer, but more active macrophages to allow for appropriate remodeling. Together, these findings suggest that treatment with niacin in the absence of adiponectin may promote rather than abrogate generalized ATM activation, and that adiponectin is necessary for niacin-mediated alterations in macrophage activation. In this study, adiponectin tissue concentrations were attenuated in WT mice through HFD feeding. It would be interesting to evaluate the effects of niacin administration to mice that had attenuated circulating levels of adiponectin, such as in heterozygous Adipoq ${ }^{+-}$mice, that may more accurately reflect the low, but not absent levels of adiponectin that are observed in people with obesity. This would provide a unique and additional approach to control the levels of adiponectin in order to evaluate the specific effects of niacin under various conditions. Further studies to evaluate protein concentration and cytokine release are needed to confirm the changes in ATM polarity. In addition, it would be interesting to determine if niacin had a similar effect on circulating monocytes and immune cells in Adipoq $q^{-/}$mice. Our findings are consistent with previous work in rodent models of obesity $[28,29,65]$, and suggest that in vivo, niacin does not drive specific macrophage polarization but rather alters generalized inflammation.

Numerous studies have demonstrated that HFD feeding and obesity contribute to increases in circulating cytokines and acute phase proteins such as CRP, TNF $\alpha$, and IL- $6[8,11,12,14]$. The role of circulating cytokines in obesity is controversial, as they are considered both damaging and protective, and cytokines such as IL-6 regulate adipose tissue macrophage polarization [66]. We wanted to determine if the mice in our study exhibit similar evidence of systemic inflammation with the development of obesity. Our findings suggest that in WT mice, HFD-induced inflammation is localized to the tissues, with no changes in circulating inflammatory cytokines. Based on the lack of significance noted in our serum adiponectin concentrations, these findings are not surprising, and may be associated with the short timeframe of HFD feeding implemented in this study. Interestingly, a lack of adiponectin has a discordant effect on local adipose tissue production of $\mathrm{Ccl} 2$ and systemic MCP-1 concentrations. This leads us to believe that the increased serum MCP-1 in Adipoq-- mice is associated with changes in inflammation other than in adipose tissue and requires further investigation. One possible consideration is the effect of HFD-induced steatosis in the liver of the Adipoq ${ }^{-1}$ mice. When fed an HFD, Adipoq ${ }^{-1}$ mice are susceptible to the development of steatohepatitis [67], and adiponectin plays a role in attenuating liver fibrosis by inducing nitric oxide [68]. A recent paper suggests that niacin inhibits oxidative stress and lipid accumulation in hepatocytes [69]. Further studies are warranted to elucidate other potential causes for the increased serum MCP-1 concentrations in HFD-fed Adipoq ${ }^{--}$mice. Niacin has also been shown to inhibit monocyte adhesion to human endothelial cells [33]. Based on these findings, it would be interesting to determine if the discordant MCP- 1 changes observed in the tissues and in circulation of Adipo $q^{-/}$mice manifest as a change in circulating monocyte numbers.

\section{Conclusions}

In conclusion, our data suggest that niacin may decrease HFD-induced ATM recruitment in an adiponectin-independent manner. The mechanism behind these changes is likely directly associated with activation of the $\mathrm{HCA}_{2}$ rather than with changes in adiponectin. The absence of adiponectin alters niacin's effects on some markers of inflammation in the adipose tissue but does not hinder its ability to reduce markers of macrophage recruitment.

Author Contributions: E.C.G. and R.L.J. were involved in the conception and design of the study, acquisition and interpretation of data, and manuscript preparation. E.C.G. was the primary author of the manuscript from initial draft to final submission. H.F. was involved in data acquisition and interpretation and D.W. was involved initial study conception, design, data interpretation, and manuscript writing and editing. All authors have read and agreed to the published version of the manuscript.

Funding: Diabetes Action Research and Education Foundation and Boshell Diabetes and Metabolic Disease Research Program. 
Acknowledgments: The authors would like to acknowledge Cynthia Tiley-Hutchison for her expertise and technical assistance.

Conflicts of Interest: The authors have no conflict of interest to disclose.

\section{References}

1. Ghanim, H.; Aljada, A.; Hofmeyer, D.; Syed, T.; Mohanty, P.; Dandona, P. Circulating mononuclear cells in the obese are in a proinflammatory state. Circulation 2004, 110, 1564-1571. [CrossRef]

2. Breslin, W.L.; Johnston, C.A.; Strohacker, K.; Carpenter, K.C.; Davidson, T.R.; Moreno, J.P.; Foreyt, J.P.; McFarlin, B.K. Obese Mexican American children have elevated MCP-1, TNF-alpha, monocyte concentration, and dyslipidemia. Pediatrics 2012, 129, e1180-e1186. [CrossRef]

3. Tzanavari, T.; Giannogonas, P.; Karalis, K.P. TNF-alpha and obesity. Curr. Dir. Autoimmun. 2010, 11, $145-156$.

4. Duffaut, C.; Galitzky, J.; Lafontan, M.; Bouloumié, A. Unexpected trafficking of immune cells within the adipose tissue during the onset of obesity. Biochem. Biophys. Res. Commun. 2009, 384, 482-485. [CrossRef]

5. Oh, D.Y.; Morinaga, H.; Talukdar, S.; Bae, E.J.; Olefsky, J.M. Increased macrophage migration into adipose tissue in obese mice. Diabetes 2012, 61, 346-354. [CrossRef]

6. Cinti, S.; Mitchell, G.; Barbatelli, G.; Murano, I.; Ceresi, E.; Faloia, E.; Wang, S.; Fortier, M.; Greenberg, A.S.; Obin, M.S. Adipocyte death defines macrophage localization and function in adipose tissue of obese mice and humans. J. Lipid Res. 2005, 46, 2347-2355. [CrossRef]

7. Lumeng, C.N.; Bodzin, J.L.; Saltiel, A.R. Obesity induces a phenotypic switch in adipose tissue macrophage polarization. J. Clin. Investig. 2007, 117, 175-184. [CrossRef]

8. Guarner, V.; Rubio-Ruiz, M.E. Low-grade systemic inflammation connects aging, metabolic syndrome and cardiovascular disease. Interdiscip. Top. Gerontol. 2015, 40, 99-106.

9. Khodabandeloo, H.; Gorgani-Firuzjaee, S.; Panahi, S.; Meshkani, R. Molecular and cellular mechanisms linking inflammation to insulin resistance and beta-cell dysfunction. Transl. Res. 2015, 167, 228-256. [CrossRef]

10. Xu, H.; Barnes, G.T.; Yang, Q.; Tan, G.; Yang, D.; Chou, C.J.; Sole, J.; Nichols, A.; Ross, J.S.; Tartaglia, L.A.; et al. Chronic inflammation in fat plays a crucial role in the development of obesity-related insulin resistance. J. Clin. Investig. 2003, 112, 1821-1830. [CrossRef]

11. Chang, C.J.; Jian, D.Y.; Lin, M.W.; Zhao, J.Z.; Ho, L.T.; Juan, C.C. Evidence in obese children: Contribution of hyperlipidemia, obesity-inflammation, and insulin sensitivity. PLoS ONE 2015, 10, e0125935. [CrossRef]

12. Takahashi, K.; Mizuarai, S.; Araki, H.; Mashiko, S.; Ishihara, A.; Kanatani, A.; Itadani, H.; Kotani, H. Adiposity elevates plasma MCP-1 levels leading to the increased CD11b-positive monocytes in mice. J. Biol. Chem. 2003, 278, 46654-46660. [CrossRef]

13. Christiansen, T.; Richelsen, B.; Bruun, J.M. Monocyte chemoattractant protein-1 is produced in isolated adipocytes, associated with adiposity and reduced after weight loss in morbid obese subjects. Int. J. Obes. 2005, 29, 146-150. [CrossRef]

14. Choi, J.; Joseph, L.; Pilote, L. Obesity and C-reactive protein in various populations: A systematic review and meta-analysis. Obes. Rev. 2013, 14, 232-244. [CrossRef]

15. Poitou, C.; Dalmas, E.; Renovato, M.; Benhamo, V.; Hajduch, F.; Abdennour, M.; Kahn, J.F.; Veyrie, N.; Rizkalla, S.; Fridman, W.H.; et al. CD14dimCD16+ and CD14+CD16+ monocytes in obesity and during weight loss: Relationships with fat mass and subclinical atherosclerosis. Arterioscler. Thromb. Vasc. Biol. 2011, 31, 2322-2330. [CrossRef]

16. Silha, J.V.; Krsek, M.; Skrha, J.V.; Sucharda, P.; Nyomba, B.L.; Murphy, L.J. Plasma resistin, adiponectin and leptin levels in lean and obese subjects: Correlations with insulin resistance. Eur. J. Endocrinol. 2003, 149, 331-335. [CrossRef]

17. Arita, Y.; Kihara, S.; Ouchi, N.; Takahashi, M.; Maeda, K.; Miyagawa, J.; Hotta, K.; Shimomura, I.; Nakamura, T.; Miyaoka, K.; et al. Paradoxical decrease of an adipose-specific protein, adiponectin, in obesity. Biochem. Biophys. Res. Commun. 1999, 257, 79-83. [CrossRef]

18. Hotta, K.; Funahashi, T.; Bodkin, N.L.; Ortmeyer, H.K.; Arita, Y.; Hansen, B.C.; Matsuzawa, Y. Circulating concentrations of the adipocyte protein adiponectin are decreased in parallel with reduced insulin sensitivity during the progression to type 2 diabetes in rhesus monkeys. Diabetes 2001, 50, 1126-1133. [CrossRef]

19. Pyrzak, B.; Ruminska, M.; Popko, K.; Demkow, U. Adiponectin as a biomarker of the metabolic syndrome in children and adolescents. Eur. J. Med. Res. 2010, 15, 147-151. [CrossRef] 
20. Dagogo-Jack, S.; Fanelli, C.; Paramore, D.; Brothers, J.; Landt, M. Plasma leptin and insulin relationships in obese and nonobese humans. Diabetes 1996, 45, 695-698. [CrossRef]

21. Ouchi, N.; Walsh, K. Adiponectin as an anti-inflammatory factor. Clin. Chim. Acta 2007, 380, 24-30. [CrossRef]

22. Ohashi, K.; Parker, J.L.; Ouchi, N.; Higuchi, A.; Vita, J.A.; Gokce, N.; Pedersen, A.A.; Kalthoff, C.; Tullin, S.; Sams, A.; et al. Adiponectin promotes macrophage polarization toward an anti-inflammatory phenotype. J. Biol. Chem. 2010, 285, 6153-6160. [CrossRef]

23. Mandal, P.; Pratt, B.T.; Barnes, M.; McMullen, M.R.; Nagy, L.E. Molecular mechanism for adiponectin-dependent M2 macrophage polarization: Link between the metabolic and innate immune activity of full-length adiponectin. J. Biol. Chem. 2011, 286, 13460-13469. [CrossRef]

24. Arita, Y.; Kihara, S.; Ouchi, N.; Maeda, K.; Kuriyama, H.; Okamoto, Y.; Kumada, M.; Hotta, K.; Nishida, M.; Takahashi, M.; et al. Adipocyte-derived plasma protein adiponectin acts as a platelet-derived growth factor-BB-binding protein and regulates growth factor-induced common postreceptor signal in vascular smooth muscle cell. Circulation 2002, 105, 2893-2898. [CrossRef]

25. Yokota, T.; Oritani, K.; Takahashi, I.; Ishikawa, J.; Matsuyama, A.; Ouchi, N.; Kihara, S.; Funahashi, T.; Tenner, A.J.; Tomiyama, Y.; et al. Adiponectin, a new member of the family of soluble defense collagens, negatively regulates the growth of myelomonocytic progenitors and the functions of macrophages. Blood J. Am. Soc. Hematol. 2000, 96, 1723-1732.

26. Ruparelia, N.; Digby, J.E.; Choudhury, R.P. Effects of niacin on atherosclerosis and vascular function. Curr. Opin. Cardiol. 2011, 26, 66-70. [CrossRef]

27. Digby, J.E.; Martinez, F.; Jefferson, A.; Ruparelia, N.; Chai, J.; Wamil, M.; Greaves, D.R.; Choudhury, R.P. Anti-inflammatory effects of nicotinic acid in human monocytes are mediated by GPR109A dependent mechanisms. Arterioscler. Thromb. Vasc. Biol. 2012, 32, 669-676. [CrossRef]

28. Wanders, D.; Graff, E.C.; White, B.D.; Judd, R.L. Niacin increases adiponectin and decreases adipose tissue inflammation in high fat diet-fed mice. PLOS ONE 2013, 8, e71285. [CrossRef]

29. Lukasova, M.; Malaval, C.; Gille, A.; Kero, J.; Offermanns, S. Nicotinic acid inhibits progression of atherosclerosis in mice through its receptor GPR109A expressed by immune cells. J. Clin. Investig. 2011, 121, 1163-1173. [CrossRef]

30. Digby, J.E.; McNeill, E.; Dyar, O.J.; Lam, V.; Greaves, D.R.; Choudhury, R.P. Anti-inflammatory effects of nicotinic acid in adipocytes demonstrated by suppression of fractalkine, RANTES, and MCP-1 and upregulation of adiponectin. Atherosclerosis 2010, 209, 89-95. [CrossRef]

31. Wu, B.J.; Chen, K.; Barter, P.J.; Rye, K.A. Niacin inhibits vascular inflammation via the induction of heme oxygenase-1. Circulation 2012, 125, 150-158. [CrossRef] [PubMed]

32. Wu, B.J.; Yan, L.; Charlton, F.; Witting, P.; Barter, P.J.; Rye, K.A. Evidence that niacin inhibits acute vascular inflammation and improves endothelial dysfunction independent of changes in plasma lipids. Arterioscler. Thromb. Vasc. Biol. 2010, 30, 968-975. [CrossRef] [PubMed]

33. Ganji, S.H.; Qin, S.; Zhang, L.; Kamanna, V.S.; Kashyap, M.L. Niacin inhibits vascular oxidative stress, redox-sensitive genes, and monocyte adhesion to human aortic endothelial cells. Atherosclerosis 2009, 202, 68-75. [CrossRef] [PubMed]

34. Schaub, A.; Futterer, A.; Pfeffer, K. PUMA-G, an IFN-gamma-inducible gene in macrophages is a novel member of the seven transmembrane spanning receptor superfamily. Eur. J. Immunol. 2001, 31, 3714-3725. [CrossRef]

35. Ahmed, K.; Tunaru, S.; Offermanns, S. GPR109A, GPR109B and GPR81, a family of hydroxy-carboxylic acid receptors. Trends Pharmacol. Sci. 2009, 30, 557-562. [CrossRef] [PubMed]

36. Offermanns, S.; Colletti, S.L.; Lovenberg, T.W.; Semple, G.; Wise, A.; AP, I.J. International Union of Basic and Clinical Pharmacology. LXXXII: Nomenclature and Classification of Hydroxy-carboxylic Acid Receptors (GPR81, GPR109A, and GPR109B). Pharmacol. Rev. 2011, 63, 269-290. [CrossRef]

37. Graff, E.C.; Fang, H.; Wanders, D.; Judd, R.L. Anti-inflammatory effects of the hydroxycarboxylic acid receptor 2. Metabolism. 2016, 65, 102-113. [CrossRef]

38. Lee, J.M.; Robson, M.D.; Yu, L.M.; Shirodaria, C.C.; Cunnington, C.; Kylintireas, I.; Digby, J.E.; Bannister, T.; Handa, A.; Wiesmann, F.; et al. Effects of high-dose modified-release nicotinic acid on atherosclerosis and vascular function: A randomized, placebo-controlled, magnetic resonance imaging study. J. Am. Coll. Cardiol. 2009, 54, 1787-1794. [CrossRef] 
39. Fraterrigo, G.; Fabbrini, E.; Mittendorfer, B.; O’Rahilly, S.; Scherer, P.E.; Patterson, B.W.; Klein, S. Relationship between changes in plasma adiponectin concentration and insulin sensitivity after niacin therapy. Cardiorenal Med. 2012, 2, 211-217. [CrossRef]

40. Hu, M.; Yang, Y.L.; Masuda, D.; Yamashita, S.; Tomlinson, B. Effect of Extended-Release Niacin/Laropiprant Combination on Plasma Adiponectin and Insulin Resistance in Chinese Patients with Dyslipidaemia. Dis. Markers 2015, 2015, 154014. [CrossRef]

41. Westphal, S.; Borucki, K.; Taneva, E.; Makarova, R.; Luley, C. Adipokines and treatment with niacin. Metabolism 2006, 55, 1283-1285. [CrossRef] [PubMed]

42. Plaisance, E.P.; Lukasova, M.; Offermanns, S.; Zhang, Y.; Cao, G.; Judd, R.L. Niacin stimulates adiponectin secretion through the GPR109A receptor. Am. J. Physiol. Endocrinol. Metab. 2009, 296, E549-E558. [CrossRef] [PubMed]

43. Pfaffl, M.W. A new mathematical model for relative quantification in real-time RT-PCR. Nucleic Acids Res. 2001, 29, e45. [CrossRef] [PubMed]

44. Luo, Y.; Burrington, C.M.; Graff, E.C.; Zhang, J.; Judd, R.L.; Suksaranjit, P.; Kaewpoowat, Q.; Davenport, S.K.; O'Neill, A.M.; Greene, M.W. Metabolic phenotype and adipose and liver features in the high fat Western diet-induced mouse model of obesity-linked NAFLD. Am. J. Physiol. Endocrinol. Metab. 2015, 310, 418-439. [CrossRef]

45. Offermanns, S.; Schwaninger, M. Nutritional or pharmacological activation of HCA ameliorates neuroinflammation. Trends Mol. Med. 2015, 21, 245-255. [CrossRef]

46. Singh, N.; Gurav, A.; Sivaprakasam, S.; Brady, E.; Padia, R.; Shi, H.; Thangaraju, M.; Prasad, P.D.; Manicassamy, S.; Munn, D.H.; et al. Activation of the receptor (Gpr109a) for niacin and the commensal metabolite butyrate suppresses colonic inflammation and carcinogenesis. Immunity 2014, 40, 128-139. [CrossRef]

47. Plaisance, E.P.; Grandjean, P.W.; Brunson, B.L.; Judd, R.L. Increased total and high-molecular weight adiponectin after extended-release niacin. Metabolism 2008, 57, 404-409. [CrossRef]

48. Westphal, S.; Luley, C. Preferential increase in high-molecular weight adiponectin after niacin. Atherosclerosis 2008, 198, 179-183. [CrossRef]

49. Hu, E.; Liang, P.; Spiegelman, B.M. AdipoQ is a novel adipose-specific gene dysregulated in obesity. J. Biol. Chem. 1996, 271, 10697-10703. [CrossRef]

50. Chaolu, H.; Asakawa, A.; Ushikai, M.; Li, Y.X.; Cheng, K.C.; Li, J.B.; Zoshiki, T.; Terashi, M.; Tanaka, C.; Atsuchi, K.; et al. Effect of exercise and high-fat diet on plasma adiponectin and nesfatin levels in mice. Exp. Ther. Med. 2011, 2, 369-373. [CrossRef]

51. Kim, S.P.; Nam, S.H.; Friedman, M. Mechanism of the antiadipogenic-antiobesity effects of a rice hull smoke extract in 3T3-L1 preadipocyte cells and in mice on a high-fat diet. Food Funct. 2015, 6, 2939-2948. [CrossRef] [PubMed]

52. Justo, M.L.; Claro, C.; Zeyda, M.; Stulnig, T.M.; Herrera, M.D.; Rodriguez-Rodriguez, R. Rice bran prevents high-fat diet-induced inflammation and macrophage content in adipose tissue. Eur. J. Nutr. 2015, 55, 2011-2019. [CrossRef] [PubMed]

53. Kentish, S.J.; Ratcliff, K.; Li, H.; Wittert, G.A.; Page, A.J. High fat diet induced changes in gastric vagal afferent response to adiponectin. Physiol. Behav. 2015, 152, 354-362. [CrossRef] [PubMed]

54. Holness, C.L.; Simmons, D.L. Molecular cloning of CD68, a human macrophage marker related to lysosomal glycoproteins. Blood 1993, 81, 1607-1613. [CrossRef] [PubMed]

55. Yu, R.; Kim, C.S.; Kwon, B.S.; Kawada, T. Mesenteric adipose tissue-derived monocyte chemoattractant protein-1 plays a crucial role in adipose tissue macrophage migration and activation in obese mice. Obesity 2006, 14, 1353-1362. [CrossRef]

56. Weisberg, S.P.; Hunter, D.; Huber, R.; Lemieux, J.; Slaymaker, S.; Vaddi, K.; Charo, I.; Leibel, R.L.; Ferrante, A.W. CCR2 modulates inflammatory and metabolic effects of high-fat feeding. J. Clin. Investig. 2006, 116, 115-124. [CrossRef]

57. Kanda, H.; Tateya, S.; Tamori, Y.; Kotani, K.; Hiasa, K.; Kitazawa, R.; Kitazawa, S.; Miyachi, H.; Maeda, S.; Egashira, K.; et al. MCP-1 contributes to macrophage infiltration into adipose tissue, insulin resistance, and hepatic steatosis in obesity. J. Clin. Investig. 2006, 116, 1494-1505. [CrossRef] 
58. Kamei, N.; Tobe, K.; Suzuki, R.; Ohsugi, M.; Watanabe, T.; Kubota, N.; Ohtsuka-Kowatari, N.; Kumagai, K.; Sakamoto, K.; Kobayashi, M.; et al. Overexpression of monocyte chemoattractant protein-1 in adipose tissues causes macrophage recruitment and insulin resistance. J. Biol. Chem. 2006, 281, 26602-26614. [CrossRef]

59. Shi, Y.; Lai, X.; Ye, L.; Chen, K.; Cao, Z.; Gong, W.; Jin, L.; Wang, C.; Liu, M.; Liao, Y.; et al. Activated niacin receptor HCA2 inhibits chemoattractant-mediated macrophage migration via Gbetagamma/PKC/ERK1/2 pathway and heterologous receptor desensitization. Sci. Rep. 2017, 7, 42279. [CrossRef]

60. Hillyer, P.; Mordelet, E.; Flynn, G.; Male, D. Chemokines, chemokine receptors and adhesion molecules on different human endothelia: Discriminating the tissue-specific functions that affect leucocyte migration. Clin. Exp. Immunol. 2003, 134, 431-441. [CrossRef]

61. Thomas, D.; Apovian, C. Macrophage functions in lean and obese adipose tissue. Metabolism 2017, 72, 120-143. [CrossRef] [PubMed]

62. Morris, D.L.; Singer, K.; Lumeng, C.N. Adipose tissue macrophages: Phenotypic plasticity and diversity in lean and obese states. Curr. Opin. Clin. Nutr. Metab. Care 2011, 14, 341-346. [CrossRef] [PubMed]

63. Mosser, D.M.; Edwards, J.P. Exploring the full spectrum of macrophage activation. Nat. Rev. Immunol. 2008, 8, 958-969. [CrossRef] [PubMed]

64. Wernstedt Asterholm, I.; Tao, C.; Morley, T.S.; Wang, Q.A.; Delgado-Lopez, F.; Wang, Z.V.; Scherer, P.E. Adipocyte Inflammation Is Essential for Healthy Adipose Tissue Expansion and Remodeling. Cell Metab. 2014, 20, 103-118. [CrossRef] [PubMed]

65. Lipszyc, P.S.; Cremaschi, G.A.; Zorrilla-Zubilete, M.; Bertolino, M.L.; Capani, F.; Genaro, A.M.; Wald, M.R. Niacin Modulates Pro-inflammatory Cytokine Secretion. A Potential Mechanism Involved in its Anti-atherosclerotic Effect. Open Cardiovasc. Med. J. 2013, 7, 90-98. [CrossRef] [PubMed]

66. Mauer, J.; Chaurasia, B.; Goldau, J.; Vogt, M.C.; Ruud, J.; Nguyen, K.D.; Theurich, S.; Hausen, A.C.; Schmitz, J.; Brönneke, H.S.; et al. Signaling by IL-6 promotes alternative activation of macrophages to limit endotoxemia and obesity-associated resistance to insulin. Nat. Immunol. 2014, 15, 423-430. [CrossRef] [PubMed]

67. Asano, T.; Watanabe, K.; Kubota, N.; Gunji, T.; Omata, M.; Kadowaki, T.; Ohnishi, S. Adiponectin knockout mice on high fat diet develop fibrosing steatohepatitis. J. Gastroenterol. Hepatol. 2009, 24, 1669-1676. [CrossRef]

68. Dong, Z.; Su, L.; Esmaili, S.; Iseli, T.J.; Ramezani-Moghadam, M.; Hu, L.; Xu, A.; George, J.; Wang, J. Adiponectin attenuates liver fibrosis by inducing nitric oxide production of hepatic stellate cells. J. Mol. Med. 2015, 93, 1327-1339. [CrossRef]

69. Ganji, S.H.; Kashyap, M.L.; Kamanna, V.S. Niacin inhibits fat accumulation, oxidative stress, and inflammatory cytokine IL-8 in cultured hepatocytes: Impact on non-alcoholic fatty liver disease. Metabolism 2015, 64, 982-990. [CrossRef]

(C) 2020 by the authors. Licensee MDPI, Basel, Switzerland. This article is an open access article distributed under the terms and conditions of the Creative Commons Attribution (CC BY) license (http://creativecommons.org/licenses/by/4.0/). 